Derecho \& Realidad

Núm. 22 • II semestre de 2013

Facultad de Derecho y Ciencias Sociales, UPTC

ISSN: 1692-3936

\title{
Estado y democracia en Elías Díaz (del Estado social y democrático de derecho)
}

\author{
State and democracy in ElíasDíaz \\ (From the social and democratic State of Law)
}

Miguel Hernández García*

Resumen

El Estado de derecho se construye como proceso histórico racional en constante revisión y crítica. La evolución histórica de los distintos modelos por los que atraviesa esta formación jurídico-política no aísla con caracteres esencialistas los distintos modelos, sino que integra una triple profundización progresiva: de los principios éticos y prescripciones morales que subyacen a los derechos humanos y libertades fundamentales, como democracia moral, de la plural participación activa como democracia política y de la institucionalización de las anteriores para protección y garantía de las mismas, como democracia jurídica.

De esta forma, la universalización de la democratización de la vida pública que está llamada a evidenciarse en el Estado social y democrático de derecho, se presenta como una realidad inacabada hacia la que propender constantemente. La plural participación responsable y comprometida y la solidaridad de la sociedad civil, junto con la responsabilidad de las instituciones jurídico-

* Magíster Universidad Carlos III. Asesor Acadeum. 
políticas, dan forma al socialismo democrático, con el cual se han de poder alcanzar las mejoras pretendidas en términos de justicia y equidad social.

\title{
Palabras clave
}

democracia, Estado de derecho, participación, solidaridad, compromiso, responsabilidad, justicia social, derechos humanos.

\begin{abstract}
TheState of lawis built as a rationalhistorical processunder constant review andcriticism. The historical evolution ofthe different models that flows through thislegal and politicalformation does not isolatewithessentialist characters its definition, but incorporatesa tripleprogressive deepening: ethical principlesandmoral prescriptionsthat underliehuman rights andfundamentalfreedoms, asmoraldemocracy, in pluralandactive participation aspolitical democracyand in the institutionalization, protection and guarantee of the same, as legal democracy.

Thus, universalization ofthe democratizationof public life thatis calledto be realized in thesocial and democratic Stateof law, which is presented as anunfinishedreality to work constantly. The commitment, plural andresponsible participationand solidarity ofcivilsociety, along with the increasing responsibility of legaland politicalinstitutions, give shape to democratic socialism, with which they will be able to achieve the pretended improvementsin terms ofsocial justice and equity.
\end{abstract}

\section{Key words}

democracy, State of law, participation, solidarity, commitment, responsibility, social justice, human rights. 


\section{Introducción}

Elías Díaz García nace en la localidad de Santiago de la Puebla, en la provincia de Salamanca, España, el 5 de junio de 1934. Es licenciado en Derecho por la Universidad de Salamanca, doctor por la Universidad de Bolonia y catedrático de Filosofía del Derecho de la Universidad Autónoma de Madrid. Cofundador de la Revista Cuadernos para el Diálogo en 1963 y director de la Revista Sistema, al momento de su aparición en 1973. Intelectual histórico de la izquierda liberal y progresista, desarrolla su teoría sobre el Estado social y democrático de derecho durante los años de la dictadura en España, frente a la democracia orgánica con que pretendía legitimarse el régimen autoritario del general Francisco Franco.

Forma parte por ese tiempo de los grupos de jóvenes universitarios de oposición democrática al régimen dogmático, nacional-catolicista, reaccionario y antimoral, de "grandes y sacrosantos principios" y fanática intransigencia. En 1966 y en 1975 tuvo que comparecer ante el Tribunal del Orden Público a causa de publicaciones de sus trabajos, siendo también detenido durante el estado de excepción de 1969. Positivista decidido, se enfrenta durante el periodo franquista al iusnaturalismo más obsoleto, de corte teológico-medieval, principalmente aristotélico-tomista, el cual considera germen del fundamentalismo intolerante, negador de la autonomía moral del individuo, y por ello, opuesto a la democracia ${ }^{1}$. Igualmente, a lo largo de las décadas que siguen a la reforma pactada que permitiera la reinstauración de la democracia, se manifiesta contrario al dominio global del dogma economicista neoliberal y al pensamiento único que cobra fuerza en la cultura de la postmodernidad.

Elías Díaz analiza la realidad social y del derecho de su tiempo, adelantando, en buena medida, características que se nos antojan imperdonables en todo Estado democrático de derecho que pretenda erguirse como solución de justicia social suficientemente digna y universal en su dominio de aplicación². Ya en la España

1 Frente a la negación de relación posible entre iusnaturalismo y democracia, se puede oponer la asociación entre la Escuela Natural Racionalista de Derecho Natural. En España, el liberal Francisco Giner de los Ríos es de los filósofos iusnaturalistas que más decididamente apoyó la democracia. Pudiera sostenerse, consiguientemente, que es desacertada la equiparación excluyente entre positivismo y democracia. El positivismo jurídico también se plantea como axioma implícito y presupuesto esencial del socialismo, sobre la base de la afirmación de que el socialismo, aunque procure el bienestar del individuo, resulta necesariamente contrario al Derecho Natural por cuanto entiende a la Persona ante todo como parte de un todo social. Una posible contestación a este planteamiento se encuentra en el hecho de que el socialismo aparezca claramente vinculado a la ética del humanismo que ensalza la autonomía del individuo y considera al ser humano como un fin en sí mismo.

2 Hace aún no tantas décadas, en España se luchaba también desde el Derecho contra la dictadura; hoy, desde la rigidez y la justicia constitucional, se trata de garantizar el efectivo funcionamiento de una sociedad democrática avanzada. 
democrática, el docente e investigador, catedrático emérito de Filosofía del Derecho por la Universidad Autónoma de Madrid, continúa desarrollando su pensamiento dedicado al análisis de los problemas sociales, políticos y culturales del mundo contemporáneo. Principalmente estudia dos áreas temáticas, a saber, de una parte los asuntos de la filosofía ética y jurídico-política, y de manera especial el Estado social y democrático de derecho y la teoría de la justicia y de los derechos humanos, y de otra parte, la historia de las ideas políticas y sociales de la España contemporánea, reconstruyendo y recuperando las tesis críticas-pluralistas impedidas hasta el momento de la recuperación de la democracia.

Ha sido asesor de la Comisión Constitucional del Partido Socialista Obrero Español y director, después, del Centro de Estudios Políticos y Constitucionales ${ }^{3}$, así como premio "Pablo Iglesias" de Ciencias Sociales en 1984 y premio Castilla y León de Ciencias Sociales y Comunicación en 1986. Doctor Honoris Causa por la Universidad Carlos III de Madrid en 2002, por la Universidad de Milán en 2006, y por la Universidad de Alicante en 2008, ha publicado numerosos ensayos, artículos y libros, y pronunciado conferencias en numerosas universidades, centros culturales y de investigación, tanto españoles como europeos y americanos.

Elías Díaz estudia la ciencia del derecho, la filosofía del derecho y la sociología del derecho desde la perspectiva histórica ${ }^{4}$. Es uno de los autores que más ha contribuido a elevar el prestigio y el reconocimiento internacional de la filosofía del derecho en lengua castellana, así como la notable influencia de la cultura jurídica española en la región latina ${ }^{5}$. El autor revisa la función crítica que toda filosofía debe contener, y desde esa prudencia, desarrolla un aperturismo integrador que se evidencia en el compromiso de lo académico con lo social que éste representa. En su obra Sociología y filosofía del derecho (1977) renueva ciertos temas y métodos en la tradicional filosofía del derecho española. En este título, se revisan algunos de los filósofos del derecho más destacados del siglo XX, ofreciendo una visión revitalizada de la

\footnotetext{
3 Estamos aquí al servicio del Estado, y todos debemos contribuir a una regeneración democrática que resguarde los valores y principios esenciales de la Constitución, al tiempo que ofrezca una respuesta eficaz a las inquietudes de los ciudadanos. Esta es la Carta de Presentación del Centro de Estudios Políticos y Constitucionales, Organismo dependiente del Ministerio Español de la Presidencia, cuya misión consiste en fomentar el análisis de la realidad jurídica y sociopolítica nacional e internacional, prestando especial atención a todas aquellas cuestiones relativas al Derecho español y a las instituciones de países iberoamericanos, así como a las relaciones de estos con Europa.

4 La ciencia del derecho es un análisis interno de la normatividad del derecho que tiene por objeto el derecho válido. Distingue entre validez, eficacia y legitimidad del derecho, pero se centra en las normas jurídicas válidas y vigentes. La filosofía del derecho se centra en el análisis de la legitimidad del derecho, como crítica racional y objetiva de los sistemas de las ideologías jurídicas imperantes en las sociedades de cada tiempo. La Sociología Jurídica supone un estudio externo a la norma jurídica, investigando los factores sociales que subyacen a la génesis y transformación del derecho.

5 A este respecto, cabe citar, entre otros, los aportes de autores como Eugenio Bulygin, Ernesto Garzón Valdés, Carlos Alchourron o Carlos Nino.
} 
cultura jurídica desde la teoría de autores como Kelsen, Hart o Bobbio, en lo que constituye una teoría analítica del derecho. Con marcado afán de síntesis y de superación de modelos aislacionistas, sostiene que la filosofía jurídica ha de avanzar en su futuro más próximo en su creciente interrelación con las demás ciencias de la realidad social y con la Filosofía moral y política, y que el derecho ha de acercarse a la totalidad social, recordando que la libertad, la igualdad y la solidaridad son principios que aún no han sido realizados satisfactoriamente ${ }^{6}$.

En Estado de derecho y sociedad democrática(Díaz, 1966), publicado por primera vez en 1966, tras ser objeto previamente de secuestro gubernativo, o a través de la revista Cuadernos para el Diálogo, contribuye a la creación y extensión de la cultura nacional democrática de varias generaciones de universitarios españoles. Igualmente impregna de practicidad social y política la filosofía del derecho en España. Según el filósofo del derecho, en sociedad nunca se deja de lado el "ser político", de la misma forma como la política impregna toda teoría del derecho. El constitucionalismo en Elías Díaz cuenta con un pronunciado carácter de perspectiva social y política crítica, la cual se evidencia en sus exigencias de participación pública ciudadana. Confía en que la democracia real permitirá institucionalizar, sobre la base de la legalidad y de la legitimidad, los valores del socialismo de estado y de la ética pública.

\section{Estado de derecho y constitucionalismo democrático}

Elías Díaz describe el Estado de derecho como la institucionalización jurídica de la democracia, en su inevitable conexión con esta, de fondo, fáctica y prescriptiva. Las características y exigencias de este tipo de sistema político-constitucional se contraponen a las propias de los Estados absolutos, totalitarios, dictatoriales o autoritarios. La protección de las libertades y derechos fundamentales constituye la razón de ser del Estado de derecho, cuya garantía jurídica se correlaciona con el moderno constitucionalismo caracterizado por la primacía de la norma constitucional y las demás normas que conforman el llamado bloque de constitucionalidad, sobre las demás normas de rango inferior; por la separación de las funciones en el ejercicio del poder, legislativo, ejecutivo, judicial, ${ }^{7}$ con predominio en última instancia del legislativo, primer poder constitucional ${ }^{8}$; y por una correcta fiscalización en la

$6 \quad$ La filosofía jurídica está, con mayor sentido y premura que nunca, si se permite aclararse así, en deuda con su razón de ser y debida función, como base de las propuestas económicas, sociales y culturales de los Estados y de la Comunidad Internacional.

7 En este sentido, la Constitución francesa de 1791 señala en su artículo 16 que: "Toda sociedad en la cual la garantía de los derechos no esté asegurada, ni se adopte la separación de poderes, carece de Constitución".

8 La institución que representa la soberanía popular es la que suministra la legalidad y la legitimidad a la institución que ejerce la acción gubernamental, aclara Elías Díaz. 
administración de la cosa pública, con una acción ejecutiva capaz de hacer prevalecer el interés general de la sociedad en la acción intervencionista del Estado9 . Lo anterior supone sometimiento del mismo Estado a su propio derecho, regulación y control de todos sus poderes y actuaciones por medio de leyes creadas según determinados procedimientos de abierta y libre participación popular. Esto es, imperio del ordenamiento jurídico como expresión de la voluntad popular sobre gobernantes y ciudadanos, producto de la libre participación y representación suficiente por parte de todos los sujetos de derecho.

El moderno constitucionalismo se puede definir como aquél sistema político regido por una constitución democrática, con carácter normativo y dotada de auténticos límites jurídicos al poder para garantía de las libertades y de los derechos de los individuos. Igualmente, la democracia aparece vinculada a los derechos humanos, en tanto que sistema formado de instituciones llamadas a recoger de manera operativa las mismas exigencias éticas y valores fundamentales que se encuentran tras aquellos. Esta sujeción del poder normativo del legislador democrático a límites materiales representados principalmente en los derechos fundamentales es un elemento consustancial, definitorio del moderno constitucionalismo democrático. Su recorrido histórico, sobre la base de la filosofía de la Ilustración y del Humanismo ${ }^{10}$, a lo largo del siglo XX puede observarse en su carácter liberal primero, social, democrático y, finalmente, cultural $^{11}$. La lógica interna de la libertad y del racionalismo ilustrado constituye una solución histórica crítica con la desigualdad social. De esta forma, el Estado de derecho se construye, lenta y trabajosamente,

9 Existe cierto paralelismo entre el Estado social de derecho y el Estado de bienestar caracterizado por una creciente prestación de servicios públicos de interés general como son los relativos a la educación, salud, asistencia y seguridad social, vivienda, prestaciones por desempleo y por jubilación, o el sistema impositivo progresivo y la redistribución de la riqueza.

10 Los reclamos de unificación del fraccionado poder privilegiado medieval en suprema y única soberanía popular representada en el Estado moderno marcan el origen remoto del Estado de Derecho. Cabe mencionar las declaraciones de derechos: inglesa de 1689 (Bill of Rights), americana en 1776, la Revolución francesa, la Declaración de los Derechos del Hombre y del Ciudadano de 1789, o el idealismo alemán.

11 Esta secuencia tiene cierta correspondencia con la trayectoria de las exigencias de reconocimiento de derechos y con su consecución y materialización constitucional. En esta se pueden destacar en un primer momento reivindicación de los derechos de sufragio activo y pasivo, reconocimiento de los partidos políticos, libertad de conciencia, de culto, de opinión y de expresión; posteriormente los derechos sociales, muchos de los cuales están estrechamente vinculados al ámbito laboral, obreroindustrial, agrario y rural, como son los derechos de asociación, reunión, sindicación, huelga, o el derecho de acceso a la riqueza. Finalmente, derechos colectivos de interés general, producto de los desafíos que entrañan los desarrollos socioeconómicos, como es el caso de los derechos ambientales. Sobre este punto se puede sostener un constitucionalismo democrático exigente ha de atender de manera integral a todos los desarrollos sociales, políticos, económicos y culturales para realizarse enteramente con coherencia y capacidad. Sólo la asunción completa y simultánea de todas las manifestaciones de la ética pública, de todos los valores, intereses y expectativas ciudadanas, generando y orientando constantemente la acción política del Estado y la gestión del bien común confiere legitimidad un sistema constitucional pretendidamente social y democrático de derecho. 
al compás de los logros constitucionales en materia de exigencia de seguridad, libertad, propiedad e igualdad, como la base de una teoría de Estado y de justicia.

Encuadrado en los sistemas occidentales democrático-liberales, el tránsito del Estado liberal de derecho al Estado social de derecho, y de éste al Estado social y democrático de derecho, se corresponde, según el autor, al de la profundización de la doble participación ciudadana que, en su opinión, define la democracia. En primer lugar participación en las decisiones jurídico-políticas, la cual requiere una importante presencia de la sociedad civil, del tejido social articulado en las instituciones públicas, y en segundo lugar, participación en los resultados, medidos tanto en términos económicos como de reconocimiento efectivo de derechos y libertades. El incremento de la participación de los individuos en la vida política, unido a un aumento de la responsabilidad de los poderes públicos en el ejercicio de sus funciones, positiva, como intervención en los asuntos de interés general y negativa, como no interferencia en el ejercicio de la autonomía individual y social, resulta en el estrechamiento de los vínculos entre Estado, economía, sociedad y derecho. Dentro de este marco, el modelo por el que apuesta el catedrático salmantino es el del Estado social y democrático de derecho, el cual ha de tender a generalizar y universalizar su fundamentación de los derechos humanos ${ }^{12}$.

Elías Díaz advierte sobre las dificultades del tránsito al Estado social y democrático de derecho, que ha de ser, añade, pacífico y evolutivo. Sin embargo, los distintos obstáculos presentes no agotan las posibilidades de la referida transición. Así como tal posibilidad queda lejana en estados mal llamados subdesarrollados, e impedidaen Estados que no son de derecho, reconoce como hay otros sistemas distintos al Estado social de derecho por los cuales se plantea la posibilidad de llegar al Estado democrático, como v.gr. la "democracia popular" o "democracia socialista-soviética". De estas destaca algunos aspectos positivos. Concretamente señala su característica formulación del derecho suficientemente representativa e institucionalizada, con amplitud bastante, respeto efectivo y continua vigilancia del cumplimiento estricto y riguroso de las leyes; el imperio de la ley universal al servicio de la protección y respeto de los derechos de los ciudadanos afectando sin excepción a todo órgano del Estado, organizaciones sociales, funcionarios y ciudadanos. Sin embargo, también hace alusión a ciertos otros aspectos negativos, tales como la sacralización del poder personal o de partido, la falta de pluralismo y de libertad crítica al interior de las ideologías y movimientos concretos al interior del socialismo soviético, los cuales conducen a negarles, concluye, toda posibilidad de relacionarse con el Estado democrático de derecho ${ }^{13}$.

12 El contexto en que estas ideas son desarrolladas, sin duda suma valor a las mismas, lo cual es propio de ser mencionado.

13 Aunque la creciente despersonalización e institucionalización jurídica del poder en las democracias populares las dotaría con el tiempo de cierta legitimidad. 
Citando a Jacques Germain en Proceso al capitalismo (1998, p. 131), el filósofo del derecho reconoce que el capitalismo liberal no ha realizado la "economía del género humano". El debate interesante entre ambos, neocapitalismo y Estado social y democrático de derecho es el de si necesitan excluirse para existir o pueden darse conjuntamente. Sobre esta cuestión el autor recoge la ideología que subyace a cada uno de ellos. Elías Díaz insistió en las relaciones de producción como la base de la configuración de las formas de organización social y política, y con ello en la relación del tránsito del capitalismo al socialismo, y correlativo tránsito de democracia formal a democracia real. En todo caso, considera que la sociedad occidental capitalista sí es una sociedad de clases, en contra de lo que en abundancia quería sostenerse. El poder económico sigue siendo en cierta medida un privilegio que bien se cuida de transmitirse hereditariamente o por cooptación. Difícilmente franqueable, comenta como la oligarquía capitalista está en estrecha conexión con el poder político.

También habla de sociedad de masas. Bajo este concepto se ha venido aludiendo a la "universalización del nivel medio de consumo". O también, sociedad industrial de consumo ${ }^{14}$. Donde sea preferible no referirse a sociedad de masas, por cuanto pueda resultar un término inexacto no evidente o generalizado en todos los países y contextos, tal vez si pueda hacerse cuando menos un paralelismo con otro fenómeno no menos llamativos y seguramente más amplio que el de la masificación del consumo, cual es el de la uniformización cultural que venimos acusando desde hace tiempo y cada vez con más fuerza ${ }^{15}$. La sociedad de consumo de masas, también asociada de forma reduccionista a cierto estado de bienestar, está basada en la movilidad social y libertad neocapitalista. Sin embargo, la economía de mercado, por su parte, bien puede ser compatible con muchas crisis, además de resultar clasista, retrógrada, o también, en opinión del autor, elitista y aristocratizante, así como derivarse de una concepción típica del conservadurismo

14 La técnica y el desarrollo social democratizan. Sobre este punto cabe plantearse lo siguiente: ¿Qué fuerzas, económicas y sociales, orientan el consumo y el desarrollo tecnológico, y cultural? Esta puede ser una interesante cuestión que, sin embargo, excede las posibilidades del presente espacio.

15 De esta, la uniformización cultural, se dice que es inevitable y que, ciertamente, bien llevada puede tener sus buenas consecuencias. Son muchos los ejemplos que pueden pensarse. Con ella, se clama también el "reconocimiento de la diferencia local", de cada manifestación estética, artística o cultural en su peculiaridad propia. Las anteriores manifestaciones se preocupan de remarcar su exclusividad (razón por la cual se facilita el que se deforme y vicie la natural realidad de las cosas, perdiendo legitimidady plausibilidad, alteza y justeza de valores). Este es un caso que puede estar en la divisoria y confusión entre aspectos positivos y negativos de la mundialización aludida. La postcolonización de usos y costumbres más vistosas o mal llamadas desarrolladas también contribuye al resurgimiento de nacionalismos, difícilmente benignos en medio de esta turbulencia y, en general, a cierto rechazo a la otredad; aunque, conviene insistir, prevalecela confusión a la diferenciación entre la tipología de efectos descritos.

La técnica y el desarrollo social democratizan. Sobre este punto cabe plantearse lo siguiente: ¿Qué fuerzas, económicas y sociales, orientan el consumo y el desarrollo tecnológico, y cultural? Esta puede ser una interesante cuestión que, sin embargo, excede las posibilidades del presente espacio. 
tradicional que le tiene "horror a las masas". Elías Díaz se muestra muy crítico con el neocapitalismo, el cual, dice, puede resultar igual de despreciativo que la cultura elitista tradicional, aunque sea mucho menos explícito o evidente y emplee un lenguaje menos directo.Sin embargo, añade, el elitismo "ha perdido dramatismo", pasando del horror de las masas a la utilización (económica) de las masas. El consumidor "satisfecho ${ }^{16}$ " conviene al poder tecnócrata y económico. No hay libertad-dignidad en el consumo conformista, en la sociedad de medios asimilada, consciente o inconscientemente ${ }^{17}$.

En este sentido, la sociedad de clases, y la sociedad cultural de masas, no equivalen per se a democracia. Si bien pueden generar tendencia hacia la nivelación socioeconómica y aunque de ellas se derive cierto dinamismo legislativo que quepa presuponerse representativo de intereses sociales confirmados en la práctica, no se puede sostener que favorezcan en todo la realización del modelo democrático pretendido. Es necesario, además, que se alcance a incorporar la participación activa y generalizada del ciudadano comprometido y responsable en los desempeños y rendimientos sociales de la vida pública. La gestión solidaria y colectiva de la política y de la economía es condición imprescindible para el logro de la extensa materialización efectiva de una democracia de estado en los términos en que se plantea $^{18}$.

En relación con lo anterior, otro concepto por seguir en Elías Díaz es el de la "participación ficticia". Sobre la ficción de participación, de democracia, aclara que es necesaria en las sociedades y estados no democráticos, en buena medida debido al creciente nivel de comunicación, de conocimiento y sensibilización ciudadana. La ficción es conveniente para mantener el privilegio, la inequidad, la injusticia. A la ficción le conviene la concesión aparente de participación, de reconocimiento, y es posible gracias al mantenimiento de un cierto grado de democracia efectiva, pseudodemocracia y pseudoefectiva, siempre de forma controlada $^{19}$. Sobre este punto, mantiene la cautela de aclarar la cercanía de la

16 Consumidor entonces presuntamente satisfecho, más sólo en apariencia, como, por más, viene a evidenciar con el paso de los años el " desengaño generalizado" que arroja la evolución del sistema instituido en donde cabe enmarcar dicho consumo.

17 Durante dos décadas, se aprecia en el imaginario social la idea de la bondad de la desafortunadamente denominada "clase media", tranquilidad asimilada de cuantos ensanchaban y engrosaban tal categoría. Más recientemente el ideario colectivo girará, a partir del desengaño colectivo que trae consigo la eclosión de la actual crisis del sistema, hacia la resignación e indignación generalizadas.

18 La participación real de las masas, según el autor ha de serlo en los dos sentidos ya apuntados: en los procesos y mecanismos de controldelas decisiones y, repite, "real participación", en los rendimientos de producción.

19 "Te han cortado las alas, te han puesto dos plumas, y después te han dado permiso para volar". 
comunicación-relación existente entre las democracias reales y las de ficción, siempre ligado a cuestiones de lo económico como sector que rige los asuntos del Estado y de la administración pública. A diferencia de antiguos autoritarismos y regímenes tradicionales, hoy en la sociedad y en el estado moderno, la opresión, el engaño o la dominación resulta más sutil ${ }^{20}$. De esta forma, la manipulación de las masas con retórica y demagogia es propia de la democracia formal, la cual, siendo exigentes para con el estado actual de las cosas, vivimos en mayor o menor medida en muchos contextos llamados hoy en día democracias. La democracia formal como democracia meramente liberal, no merece stricto sensu denominarse tal, aunque si puede ser la base desde la que lograr avanzar hacia la democracia real ${ }^{21}$.

En todo caso, se concluye que ningún sistema político que prescinda abiertamente de las masas, o que se oponga explícitamente a sus pretensiones, puede hoy aspirar a un equilibrio estable y duradero, alentando la generación de esfuerzos colectivos para, desde el derecho, procurar los cambios que permitan alcanzar mejoras sociales. En ese sentido, las legítimas exigencias de la voluntad popular, constituyen reclamos de participación, de reconocimiento y de distribución. Sin embargo, se advierte también sobre las consecuencias disfuncionales del azote oligárquico-capitalista, que con distintos grados de dureza en estados y contextos diversos, impide la prevalencia de lo social y con ello de una vera democracia real, esto es, una "democratización social de la economía". Se hace necesaria por ello la garantía de que las élites dirigentes, que se pretendan democráticas, se preocupen activamente y de forma indiscutida de que la participación, y las demás virtudes del sistema democrático, sean realmente extendidas prácticas sociales.

20 Abundando en la cuestión, las manifestaciones y protestas organizadas son un buen ejemplo de práctica social extendida, del cual, sin desmerecer aquello que de fructífero a su fin o de impacto positivo tengan o aporten, se viene alertando sus consecuencias negativas para el funcionamiento real de una democracia efectiva. Las dinámicas democráticas parecen propensas a tergiversar, de forma no deseable, su más debido sentido propio, tendiendo marcadamente a la acomodaciónde los desarrollos sociales que más pueden perjudicarla. Cierto conservadurismose impone, principalmente vía legalidad positiva, antes precisamente de que se materialice la potencialidad transformadora de la crítica social. Esta progresiva adaptación, así forzada, se gestiona a base de concesiones, control y dirigismo propia del poder político previsor, de de ser realmente democrático. El poder hace suyas esas prácticas, las intenta rechazar, o modular con mayor o menor intensidad según los casos, para después intentar mostrarlo lo más posible, si no como mérito, si al menos como complacencia propia (...).

21 Atendiendo al sentido pretendido para el término Democracia Real, debería éste reservarse para el Estado Social y Democrático de Derecho de tipo más participativo, incluyente, completo y progresivo que se pueda sensatamente concebir en un contexto dado. Lo anterior antepone la condición necesaria de coherencia e integridad bastantes, las cuales exigen, entereza, transparencia y concreción de responsabilidades de gobierno y de compromisos ciudadanos en el ejercicio de la vida pública económica, social y cultural, materializando una Democracia deAlta Justicia. 


\section{La transición al Estado social y democrático de derecho}

Cada vez resulta más evidente que la democracia socioeconómica es condición imprescindible para la democracia política ${ }^{22}$. Es por tanto necesario un paso del capitalismo al socialismo, esto es, una transición al Estado social y democrático de derecho ${ }^{23}$, como propuesta tanto más válida para una posible solución de futuro y actual, ante las dificultades y problemas que han ido localizándose en el imprescindible Estado social.El análisis y comprensión de las insuficiencias y contradicciones del sistema económico e ideológico (cultural) que deriva del neocapitalismo marca, puede decirse, el sentido y los caracteres de la superación del Estado social de derecho(Díaz, 1998, p. 131). Dada la imposible conciliación total de democracia amplia y de máximos con el neocapitalismo, se entra a estimar una más ajustada correspondencia entre democracia y socialismo; y con ello, la transformación ideológica de la sociedad actual.

El tránsito del capitalismo al socialismo supone el correlativo paso de una democracia formal a una democracia material, real; Junto a otros autores como LópezAranguren, el salmantino opina, de esta manera, que es necesario llevar el socialismo al plano económico. Esto significa que el interés primero en la confluencia de economía sociedad, derecho y Estado, no debe ser el consumo irresponsable ${ }^{24}$,

22 Sin embargo, el tipo de democracia política, consagrada en el artículo primero de la vigente Constitución Española de 1978 bajo la forma de "pluralismo político" opera, sobre este punto, tan ólo a nivel institucional y en cierta práctica menor e impotente, por cuanto, de facto, en términos de gobernabilidad efectiva se impone, con la salvedad, todo lo más, del cierto papel protagonista de algunas formaciones nacionalistas "bisagra", un bipartidismo turnista que empobrece la democracia efectiva.

23 Bien entendido, en el trasfondo de razonamientos como los anteriores se evidencia un claro presagio y clamor de cautela, un anticipo teórico fundado hacia lo que después se conocerá como crisis del bienestar. Esto tiene su importancia, dada la dificultad intrínseca al análisis de la realidad humana sin un mínimo distanciamiento temporal, y por las características donde se enmarca el surgimiento y posterior desarrollo de estas reflexiones, contextualizadas, bajo la dictadura en un ambiente de represión desmedida que las dificulta, y en democracia en el de una comodidad engañosa y optimismo traicionero que las tiende a adormecerlas.

24 Por consumo irresponsable se entiende aquél de tipo suntuoso, desmedido u opulento. Sin perder de vista el protagonismo del desempeño comercial y económico, se puede, sobre este punto, tomar la idea de consumo en una posible acepción amplia del término: aludiendo o englobando todo actuar individual y colectivo de la sociedad con implicaciones en el bienestar, desarrollo y situación de la comunidad toda ella considerada; esto es, englobando el conjunto de la cotidianeidad práctica. En ese sentido, el ritmo acelerado de las modas, la obsolescencia programada de muchos de los bienes que manejamos y de que hacemos uso diariamente, la vacuidad de valores facilitada desde una publicidad excesivamente indolente, y en general, el modelo de culturización imperante, característico de la postmodernidad urbana y digital modula los usos y costumbres en manera tal que dificulta enormemente, si no es que impide, el que tornemos globalmente hacia un modelo de consumo responsable. La dinámica cultural uniformadora e insensible a las problemáticas sociales, locales y globales, se yergue en serio obstáculo a la concienciación general sobre las implicaciones especialmente negativas del actuar normal de las personas. En relación con el tema de fondo en este texto, lo anterior complica y merma las posibilidades de una democracia legítima, comprometida, igualitaria, de permitir real y efectivamente la justicia, la equidad y la paz en sentido amplio consideradas. 
esto es, lo económico, y como un producto o resultado de tal primacía, el bienestar material de todos, luego de la redistribución paternalista del estado de bienestar ${ }^{25}$, sino más bien la ética, la igualdad, la equidad primero, esto es, una "organización social inspirada en la auténtica voluntad de justicia". Esto queda representado en la democratización económico-social, o democratización social de la economía, la cual requiere un profundo cambio cultural, de usos y costumbres, y esto, en sí, podríamos decir resulta siempre un proceso acusadamente lento ${ }^{26}$.

Lo anterior equivale, cuando menos en la concepción básica de fondo sobre las relaciones entre economía, sociedad, derecho y política, a lo que también se ha venido a denominarEstado democrático de justicia ${ }^{27}$. La institucionalización conjunta de socialismo y democracia, supera el neocapitalismo propio del Estado social de derecho. Sólo a través de la democracia y el socialismo se puede dar hoy cumplimiento real y efectivo de los derechos y libertades del ser humano y los valores de paz, igualdad, libertad y justicia. En suma, Elías Díaz aboga por una democracia de mayorías $^{28}$, en el sentido de una democracia amplia, representativa, real (subjetiva, material) y efectiva(frente al monolitismo y el dogmatismo socioeconómico). Esta conclusión conduce a retomar el hilo de la transición al Estado social y democrático de derecho en el autor, desde la óptica de la participación ciudadana que hace a la democratización de la sociedad (y con ello del Estado y de la economía) y como eje fundamental del desarrollo teórico planteado, en torno a las siguientes cuestiones:

\subsection{Transición de un intervencionismo excesivamente cuantitativo hacia uno más cualitativo y selectivo}

Elías Díaz resalta la importancia del Estado, de las instituciones jurídico-políticas, frente a los simplismos liberales por la derecha y también frente a los reduccionismos libertarios por la izquierda, aunque recuperando de estos el énfasis en la sociedad

Aunque no son estas reflexiones sobre las que continuar profundizando en el presente espacio, si se corresponden con algunos de los debates que bien podrían tomar centralidad en una renovada Sociología del Derecho, de creciente presencia en la Universidad y entre los desarrollos doctrinales de juristas comprometidos, como es preocupación y voluntad recientemente puesta de manifiesto por Elías Díaz.

25 Sin desatender la parte en que esta realidad se plantea necesaria, se tienen presente, siguiendo a Kant, las críticas acertadas al excesivo paternalismo del estado benefactor, y su correlación con la excesiva indolencia de individuos expectantes que hacen a la irresponsabilidad ciudadana.

26 Multitud de nuevas alternativas sociales que no es preciso enumerar se desarrollan hoy, continúan y profundizan el sentido de la democracia como sistema vivo. Las anteriores se sitúan en la interconexión existente entre Democracia, Derechos Humanos y Desarrollo. Sin embargo, la relación entre estos tres conceptos es tarea más densa que merita ser estudiada en otra ocasión y a los valores de paz, igualdad, libertad y justicia.

27 Estado de Justicia, concepto utilizado por López-Aranguren, el cual resulta un tanto más abstracto quizás que el de Estado Social y Democrático.

28 En Democracia no existe la totalidad, sino sólo, por definición, la mayoría. 
civil. En los años de la transición española a la democracia, apuesta por fortalecer $\mathrm{y}$ ensanchar crecientemente las funciones y cometidos del aparato estatal, para favorecer una sociedad más integrada e integradora, más participativa y más solidaria. Lo anterior viene a coexistir armoniosamente con lo que también sería, ciertamente, una relativización del sentido y razón de ser del Estado ${ }^{29} \mathrm{y}$, con ello, una reducción en la extensión de sus funciones. Queda, por tanto, aquí también, la idea del Estado que se revela demasiado grande para lo pequeño y demasiado pequeño para lo grande, en consonancia igualmente con la aparición de nuevos actores tanto a nivel interno como en el seno de la sociedad internacional y comunidad internacional $^{30}$. En todo caso, vemos como el Estado social y democrático de derecho se configura ya como un Estado atento a la moderna realidad social local y global; es pues un Estado de derecho en una sociedad-mundo o ciudadanía-cosmopolita.

Ese cambio cualitativo ha de ser el de prestar atención prevalente a los verdaderos intereses generales ${ }^{31}$. Los movimientos asociativos en defensa de intereses colectivos, compensan la presencia de lo económico, de lo profesional y de lo laboral, que tanto marcan el sentir y el rumbo de las pautas sociales y culturales. El movimiento ecologista, el feminismo o el rechazo del racismo y la xenofobia constituyen parte de los primeros ejemplos que en el contexto de la segunda mitad del siglo XX comenzaban a hacerse notar. Prontamente continúan llegando muchos otros, hasta el punto de que resultaría exhaustivo tratar de abarcar siquiera fuese la gran mayoría de ellos. Desde una ética de la competencia, se avanza progresivamente en la tendencia hacia una ética de la colaboración, atenta, en palabras del citado, a la calidad de vida más que a los productos consumidos y destruidos. Esta mayor presencia de la sociedad civil ha de serlo involucrando a todos los sectores y facetas de la misma, al margen o más allá de la denominación que se les quiera otorgar. Para ello, propone también el desarrollo de una libre auto-exigencia personal, por una ética del trabajo, del esfuerzo, del mérito, de la capacidad y la intervención participativa y solidaria ${ }^{32}$. Se trata con todo ello de la "buena ética del mundo" contra la preeminencia del capital, del individuo egoísta y de la competitividad.

29 Como suele ser habitual en estas y otras cuestiones, la solución mejor no se resuelve como "blanco o negro"; es necesaria una integración o eclecticismo de modelos híbridos, acertados y adecuados a la creciente complejidad socioeconómica que envuelve la vida pública.

30 Tras casi cuatro siglos de supremacía indiscutida del Estado-Nación, ésta comienza a resquebrajarse en los tiempos modernos merced al auge de fenómenos variados y complejos, tales como la descentralización, la mundialización (término acuñado desde la sociología y el derecho francés en referencia a la globalización), los organismos internacionales, la localización, las redes, o el poder transnacional.

31 Elías Díaz no pierde de vista que estos, el interés general, se compone, a su vez, y en parte, del sumatorio de intereses particulares legítimos, más no es oportuno a este estudio detenerse sobre este punto.

32 Por supuesto, estos presupuestos, los valores que subyacen a ellos, y sus términos y concreciones se pueden y se deben discutir, como, de hecho, bien recordaba, conocedor de las bondades de semejante ejercicio, el profesor Elías Díaz. 


\subsection{Renovada unión entre las instituciones jurídico-políticas y una sociedad civil amplia, comprometida y participativa}

"Sociológicamente el nivel de toma de conciencia y de la posibilidad efectiva de hacer valer la protesta ha aumentado en nuestro tiempo". En esta idea del citado se puede apreciar la pretensión de alcanzar una integración operativa de la acción de las grandes mayorías socio-políticas que resulte incisiva en las cuestiones más acuciantes y principales problemáticas de la ciudadanía comprometida. Con la transición al Estado social y democrático de derecho se abren las puertas para el socialismo democrático, que representa la renovada unión entre las instituciones jurídico-políticas y la sociedad civil amplia, comprometida y participativa. Es éste un nuevo modelo que irrumpe con fuerza y para bien, tal y como se viene exponiendo, frente a aquel Estado meramente "social de derecho" que llegara a convertirse, perversamente, en un "confiar todo de él”. Elías Díaz sostiene que se trata, con el socialismo democrático, de una hipotética conjunción y síntesis dialéctica entre Estado y sociedad, sin ser el fin de la historia, aclara. El socialismo democrático supera tanto al Estado social de derecho, cuanto a la socialdemocracia y a los movimientos libertarios, ello en el buen sentido, nunca descartándolos infundadamente sino aglutinando e incorporando aquello que de positivo tengan que ofrecer. El tránsito al que se hace alusión supone revitalizar el papel de la sociedad en la política. Además, se trata de dar cabida a los llamados derechos de tercera generación, los derechos de las minorías, o los derechos de solidaridad.

\subsection{Sector público de la economía y de la producción no ya tan prioritariamente estatal sino articulado a través de un más plural y dinámico sector social}

Aquí vemos parte de aquel principio mencionado de tendencia a la baja de la importancia y presencia relativa del Estado. En el Estado social y democrático de derecho se constata y denuncia la dictadura o la anarquía del mercado, el predominio del capital transnacional, especulativo, financiero, y no productivo ni social. Profundizando en las implicaciones prácticas de la teoría del jurista, se observa como propone éste superar las imposiciones del mercado nacional o internacional y del reduccionismo del análisis instrumental en el interior de la regulación fiscal. El autor insiste en una normatividad presupuestaria "impregnada de racionalidad", en aras precisamente de la consecución y satisfacción del interés general aludido. La respuesta al interrogante de ¿Cuántas demandas ha de atender el Estado?, o lo que puede equiparársele, ¿Cuánto Estado?, ha de cumplir mínimamente una triple función imprescindible, a saber, producción, selectiva y cualitativa; redistribución, proporcional y progresiva; regulación y organización, flexible y revisable; todo ello desde la doble participación del grupo que conforma la sociedad civil, entendida ésta en los amplios términos planteados. 


\subsection{El reconocimiento legal y la eficaz realización del Estado social y democrático}

El reconocimiento legal y la eficaz realización del Estado social y democrático como tal, se incluye como un último aspecto por considerar, y, viene a hacerlo para complicación y quiebra de las posibilidades reales del modelo de desplegar todo su potencial y sentido de ser. Lo anterior, claro está, no es impedimento ni mucho menos razón que justifique decaimiento en la obligada labor de trabajar en el tránsito al Estado propuesto, acaso como el más idóneo que pueda pensarse con un mínimo de responsabilidad, factibilidad, coherencia desde posiciones constitucionalistas y, ciertamente, integradoras.

La efectiva realización del derecho como sistema de seguridad y como realización de la libertad y la justicia, exige entrelazar el sistema de seguridad-legalidad del Estado de derecho y de los derechos humanos con el sistema de seguridad-legitimidad de los valores humanos y la ética pública. Con todo, según Elías Díaz, "el mundo no se acaba ni se cierra, tampoco el mundo jurídico, con los estrictos derechos subjetivos; las exigencias éticas asumidas en el ordenamiento pueden, por ejemplo, servir para orientar con fuerza, es decir, con sólidas razones, la futura legislación que dará lugar, entonces sí, a nuevos estrictos derechos"; y, continúa, "mientras tanto pueden valer (las anteriores exigencias éticas) muy bien para interpretar de un modo u otro los actuales reconocidos derechos, o para orientar coherentemente unas u otras políticas sociales". (1966, p. 217)

\section{A modo de conclusión: socialismo democrático}

"De lo que se trata hoy es de que la soberanía (oligárquica) del mercado no sustituya, subordine o anule la soberanía (democrática) del Estado" 33 .

Elías Díaz se muestra generosamente aperturista y prudente a la vez que riguroso en su estudio del Estado y de la Sociedad. Así, recorre corrientes y pensamientos variados recogiendo los elementos que, en cada propuesta de Sociedad-Estado observa más positivos para la realización práctica de los derechos y libertades de las personas. Con gran talante conciliador, transigencia y respeto de la otredad, articula su visión progresista de la realidad pública situando lo social al interior de la estatalidad y extramuros de esta, como aquella extensa y cualitativa participación ciudadana en las esferas de dominio público, y como garantía para la materialización de los valores que toda democracia exigente debe contener para realizar la idea de justicia.

33 Entrevistaa Elías Díaz, Gobierno de España, Ministerio de Ciencia e Innovación.(http:// www.tiempodelosderechos.es/es/component/content/article/110-entrevista-a-elias-diaz.html) 
El Estado social y democrático de derecho llega a partir del Estado constitucional de base liberal, más fruto principalmente de las demandas y luchas de aquellos sectores más progresistas que expandieron sus legítimas exigencias y reclamos durante los siglos XIX y XX, como son el movimiento obrero, sindical, socialista o democrático. La institucionalización conjunta de socialismo y democracia ha de suponer la superación del neocapitalismo propio del Estado social de derecho, neutralizando los efectos colaterales negativos de un desarrollo socio-económico no controlado. Para ello es preciso extender la democracia permitiendo que abarque cualitativamente todas las esferas de la vida pública, así como generalizar su alcance.

El socialismo democrático fundado en un humanismo real, amplio y libre, tiende, desde el análisis integrador de la realidad, al creciente conocimiento y compromiso general en los asuntos de interés general y de los desafíos en los procesos sociales y económicos. Las leyes no cambian si no cambia la sociedad viviendo cotidianamente los valores. En ese sentido, el estrechamiento de los vínculos entre el Estado, el mercado, la sociedad y el derecho,redunda en una mayor coherencia y responsabilidad social en la gestión de la cosa pública.

Esta es, sin embargo, una realidad inacabada y, en todo caso, del neocapitalismo no se pasa de forma natural al socialismo, por cuanto la democratización efectiva de las prácticas sociales, como de la economía, se revela en complicadísima tarea imperfectible. Por su parte, la revolución cultural que el modelo requiere, continúa frustrada. No obstante lo anterior, como se indica, la "impotencia de lo social" tiende a disminuir, permitiendo notar los avances y resultados positivos en materia de participación y pluralismo social de una ciudadanía crecientemente sensibilizada y comprometida con los asuntos de interés general.

Con todo, la estabilidad y viabilidad de un orden justo con autoridad suficiente sobre la economía plantea la realización efectiva de los conceptos de democracia moral, democracia política y democracia jurídica. El proceso, de exigencias variables e inacabables en el tiempo, se corresponde con el de la universalización de la democracia, esto es, la progresiva y constante democratizaciónjurídico-política, económica y cultural de la vida pública.

Todas las justas pretensiones, exigencias éticas y esperanzas humanas, desgraciadamente no son hoy por hoy [hoy tampoco] por completo susceptibles de juridificación de manera plena y responsable como rigurosos derechos subjetivos en el marco actual de Estado de Derecho (...) Reconozcámoslo así, con sensatas dotes de realismo para las más complicadas y difíciles de ellas, a pesar de todas las buenas intenciones y voluntades que pudieran sin duda manifestarse. Sin embargo, en modo alguno, tales voluntades e intenciones, así como los valores y los principios que las inspiran, carecen de sentido y 
transcendencia para la acción política y jurídica. En consecuencia, tales pretensiones y esperanzas no deben, por tanto, quedar fuera o al margen de los proyectos de futuro respecto a esas mencionadas transformaciones de todo tipo, desde económicas a culturales, que en cambio deben siempre impulsarse en el marco de una sociedad democrática para la necesaria construcción de un correlativo, aquí auspiciado Estado Democrático de Derecho ${ }^{34}$. (p. 217)

\section{Lista de Referencias}

Díaz, E. (2008). Aranguren: ética y política. Revista Internacional de Pensamiento Político, (3). Madrid.

Díaz, E. (1998). Cursode filosofía del derecho. Madrid:Marcial Pons.

Díaz, E. (1984). De la maldad estatal y la soberanía popular. Madrid:Debate.

Díaz, E. (2009). de la institución a la constitución: política y cultura en la españa del siglo $x x$. Madrid: Trotta.

Díaz, E. (2010). el poder de la legalidad, la razón de la legitimidad. Revista de Ciencias Sociales, (17).Madrid, Sistema.

Díaz, E. (1966). Estado de derecho y sociedad democrática. № 5, Cuadernos para el Diálogo. Madrid: EDICUSA.

Díaz, E. (1998). Estado de derecho y sociedad democrática. № 5, Cuadernos para el Diálogo. Madrid:Taurus.

Díaz, E. (1990). Ética contra política. Los intelectuales y el poder. Madrid:Centro de Estudios Constitucionales.

Tomás y Valiente, F.(2011). Intelectual crítico y hombre de estado. Revista de Ciencias Sociales, (223), 99-107. Madrid:Sistema.

Ruíz, J. (2009). Del derecho natural a los derechos naturales. Cuadernos de Filosofía del Derecho,(32), 15-36. Madrid: Doxa.

Díaz, E. (2011). La filosofía jurídica y política de Joaquín Ruíz Giménez. Madrid, Derechos y Libertades, Revista del Instituto Bartolomé de las Casas, 15 (24), 15-44 p.

34 Estado de Derecho y Democracia, (p. 217). Apuntes al libro Estado de Derecho y Sociedad Democrática. Véase más sobre el tema en Ética Pública y Estado de Derecho, Madrid, Fundación Juan Marcha, 2000, junto con Javier Muguerza, Antonio García Santesmanes, Francisco J. Laporta y Carlos Thiebaut. 
Díaz, E. (1987). La transición a la democracia, claves ideológicas, 1976-1986. Madrid: Eudema.

Díaz, E. (1998). Legalidad-legitimidad en el pensamiento democrático. Madrid:Civitas.

Díaz, E. (1994). Los viejos maestros, la reconstrucción de la razón. Madrid:Alianza.

Díaz, E. (2002). Miguel de Unamuno, europeo y liberal: implicaciones y reducciones. Madrid.Boletín de la Institución Libre de Enseñanza, (48), 2532.

Bobbio, N. (2005). La responsabilidad intelectual. Cuadernos de Filosofía del Derecho, (28), 37-49. Madrid: Doxa.

Díaz, E. (1987). Notas para una historia del pensamiento español actual (1939, 1972). Cuadernos para el Diálogo. Madrid: EDICUSA.

Díaz, E. (1992). Pensamiento español en la era de Franco (1939-1975). Madrid: Tecnos.

Díaz, E. (2005). Por un Giner de Los Ríos ni reducido ni recluido. Madrid, Boletín de la Institución Libre de Enseñanza, (58), 11-20.

Díaz, E. (2009). Realismocrítico y filosofía del derecho. Madrid:Doxa. Cuadernos de Filosofía del Derecho, (32), 91-118.

Treves, R. (2009). De Italiay España. Madrid, Derechos y libertades, Revista del Instituto Bartolomé de las Casas, 13(20), 39-46.

Díaz, E. (1968). Revisión de Unamuno, análisis crítico de su pensamiento político. Madrid: Tecnos.

Díaz, E. (2006). Salvador Giner: un sociólogo con carisma. Separata en Sistema, Revista de Ciencias Sociales,(192), 105-113.

Díaz, E. (1988). Socialismo democrático: instituciones políticas y movimientos sociales. Madrid: Centro de Estudios Constitucionales.

Díaz, E. (1982). Socialismoen España: el partido y el Estado.Madrid:Mezquita.

Díaz, E. (1977). Sociología y filosofía del derecho.Madrid: Taurus.

Díaz, E. (1965). Unamuno: pensamiento político. Madrid: Tecnos. 
Derecho y Realidad

Núm. 22 • II semestre de 2013

Facultad de Derecho y Ciencias Sociales, UPTC

ISSN: 1692-3936

\title{
La incidencia del sistema interamericano de derechos humanos en el derecho interno argentino: el caso Kimel
}

\author{
The incidence of the Inter-American system of human \\ rights in Argentine domestic law: the Kimel case
}

\author{
Esther Susana Borgarello* \\ Carlos A. Juárez Centeno**
}

\section{Resumen}

El nuevo escenario internacional produce lo que se ha dado en caracterizar como la globalización del derecho, especialmente en el ámbito de los derechos humanos. En este contexto se analiza la incidencia del sistema interamericano de protección de los derechos humanos en el derecho interno de nuestro país en aspectos relacionados con el derecho a la información.

Este escenario genera tensión en la lógica estatal, con su rasgo de afirmación de la soberanía y monopolio en la creación de jurisdicción doméstica, con la doctrina de los derechos humanos del derecho internacional que,

* Doctora en Derecho y Ciencias Sociales; profesora titular por concurso en la Escuela de Ciencias de la Información de la Facultad de Derecho y Ciencias Sociales de la UNC; categorizada 2 en el Sistema de Incentivos; directora del Departamento de Estudios Básicos de la Facultad de Derecho y Ciencias Sociales de la UNC. sb5870@gmail.com

** Abogado; especialista en Ciencia Política y Derecho Constitucional; especialista en Derechos Humanos; Diploma de Altos Estudios Internacionales; profesor titular por concurso del Área de Estudios Internacionales del Centro de Estudios Avanzados de la UNC; director de la Maestría en Relaciones Internacionales del CEA-UNC; categorizado 1 en el Sistema de Incentivos. cjuarezcenteno@gmail.com 
consecuentemente, conduce hacia una globalización jurídica en estos temas. A partir de este dato, el presente trabajo indaga concretamente en los efectos que produce la actuación de la Comisión Interamericana de Derechos Humanos y los pronunciamientos de la Corte Interamericana en la jurisprudencia y legislación argentina.

\title{
Palabras clave
}

derechos humanos, sistema interamericano de derechos humanos, libertad de expresión, derecho interno, escenario internacional, delitos contra el honor.

\begin{abstract}
The new international scenario produces what has been characterized as the globalization of law, especially in the field of human rights. In this context we analyze the impact of the Inter-American system for the protection of human rights into domestic law of our country on issues related to the right to information.

This scenario creates tension between the logic state, with its feature of assertion of sovereignty and monopoly on the creation of domestic jurisdiction, the doctrine of human rights in international law which consequently leads to a legal globalization issues. From this data, the present study specifically investigates the effects produced by the action of the Commission on Human Rights and the pronouncements of the Inter-American Court in Argentine jurisprudence and legislation.
\end{abstract}

\section{Key words}

human rights, Inter-American human rights, freedom of expression, domestic law, international scenario, crimes against honor. 


\section{Introducción}

La comunidad internacional vive nuevos tiempos, el fenómeno globalizador que día a día avanza, muestra un escenario en el que la integración e interdependencia son una constante y diluye aquel escenario westfaliano que imperó desde 1648 hasta mediados del siglo pasado. Estas transformaciones se proyectan también al campo del derecho internacional que debe adaptarse a esas nuevas dimensiones que le demanda el proceso de internacionalización. En el marco de este mundo cada vez más globalizado, el derecho internacional abarca cada vez más campos, que hasta ahora sólo eran regulados por el derecho interno de los Estados. Puede observarse, por lo tanto, un progresivo proceso de mundialización del derecho, que tuvo en el ámbito de los derechos humanos una de sus primeras vertientes.

A partir de la última mitad de siglo pasado, el reconocimiento, así como los sistemas de protección, dieron lugar a distintos instrumentos e instituciones universales y regionales, como por ejemplo el Sistema Interamericano de Derechos Humanos, que es el que opera en el ámbito del continente americano.

Esta nota distintiva del escenario internacional contemporáneo de las últimas décadas, es lo que la teoría de las relaciones internacionales ha denominado como regímenes internacionales, que se definen como el conjunto de principios, normas, reglas y procedimientos para la toma de decisiones que rige el comportamiento de los Estados en un área de la política internacional (Hasenclever, Mayer \& Rittberger, 1999, p. 499). Constituyen una clase primordial de instituciones internacionales, junto con los organismos internacionales. Son órdenes internacionales parciales, creados ex profeso con un alcance que puede ser regional o mundial. Existen en todos los ámbitos de la política mundial contemporánea: así por ejemplo en el de seguridad (como el de no proliferación), económicos, ambientales y de derechos humanos (como el surgido a partir de la Convención Americana de Derechos Humanos).

El régimen contemporáneo de derechos humanos consiste en instituciones y convenios globales, regionales y nacionales que se sobreponen. En su manifestación más global, los derechos humanos están firmemente arraigados en la Declaración Universal de los Derechos Humanos de 1948 y en varios convenios adoptados predominantemente en las décadas del 60 y 70. En 1966 se aprueban los Pactos Internacionales de Derechos Económicos, Sociales y Culturales; y el de Derechos Civiles y Políticos, si bien es cierto que ambos documentos recién entran en vigor en $1976^{1}$. A finales de la

Ambos Pactos son adoptados por Resolución 2200 de la Asamblea General de Naciones Unidas, el día 19 de diciembre de 1966. El primero entra en vigor el 30 de enero de 1976, y el segundo el 23 de marzo de igual año. El protocolo facultativo de este último, le otorga al Comité de Derechos Humanos la facultad de recibir y considerar comunicaciones de individuos que aleguen ser víctimas de violaciones a los derechos consagrados en el Pacto. 
década del setenta, en 1979, se elabora la Convención sobre la Eliminación de la Discriminación contra la Mujer, y ya en los 80, la de los Derechos del Niño. La Comisión de Derechos Humanos de Naciones Unidas se encargaba durante ese entonces de supervisar el sistema y de atraer la atención del Consejo de Seguridad hacia los abusos persistentes. Funciones que a partir de 2006 competen al Consejo de Derechos Humanos. También puede señalarse que la Organización Internacional del Trabajo (OIT) se encarga de la supervisión del área de los derechos de los trabajadores, si bien es cierto que ésta tiene un origen casi paralelo al surgimiento de la ONU, erigiéndose en su primera agencia especializada, en 1946. Por último, merece señalarse las distintas conferencias que sobre distintos aspectos de los derechos humanos se organizaron en la década del $90^{2}$.

Es importante destacar que en la actualidad, aproximadamente son 150 Estados -de un total de 192- los que han ratificado cada uno de los convenios principales de derechos humanos del sistema de Naciones Unidas. Y un creciente número de ellos aceptan las obligaciones generales de protección y provisión, así como de restricción, en sus propios procedimientos y prácticas. Si bien es cierto que muchos de estos compromisos muy rara vez están respaldados por los poderes coercitivos de ejecución, las demandas de los nuevos regímenes internacionales de derechos humanos, tanto informales como formales, han creado un sinnúmero de grupos, movimientos, agencias, letrados y activistas, todos ellos nuevos actores internacionales que persiguen la adaptación de las jurisdicciones domésticas nacionales a los parámetros de dichos regímenes que son parte integrante del derecho internacional de los derechos humanos. Este es otro dato, otro ingrediente que muestran ese gradual cambio y surgimiento de actores en el escenario internacional de los últimos tiempos.

Como se expresara, en la mayor parte de las regiones del mundo hay una estructura y una maquinaria legal equivalentes al sistema protectorio mundial. Así podemos citar como ejemplos el Convenio Europeo para la Protección de los Derechos Humanos y de las Libertades Fundamentales del 4 de noviembre de $1950^{3}$, la

$2 \quad$ La Cumbre Mundial de la Infancia de 1990, en Nueva York; la Conferencia Mundial sobre Medio Ambiente de 1992, en Río de Janeiro; la de Derechos Humanos en Viena en 1993; la Conferencia Mundial sobre Población y Desarrollo, realizada en El Cairo en 1994; las de Desarrollo Social en Copenhague y la de Derechos de la Mujer en Pekín, ambas de 1995; la de Asentamientos Urbanos en Estambul y la de Alimentación en Roma, ambas de 1996. Por último, la Conferencia Mundial contra el Racismo, realizada en Durban, en 1999. Toda esta diplomacia de las "megaconferencias", como Salvioli la ha calificado, presagiaban un cambio en la problemática en los primeros años de la post-Guerra Fría. Parecía que los derechos humanos se instalarían definitivamente en la agenda de las relaciones internacionales y también en la de sus actores principales, los Estados. La teoría y la práctica de la disciplina se encaminaba en ese sentido.

3 Su entrada en vigor es el 3 de septiembre de 1953. 
Declaración Americana (1948) y la Convención Americana de Derechos Humanos, vulgarmente conocida como Pacto de San José de Costa Rica, firmada en 1969 aunque entrada en vigor a partir de $1978^{4}$. Por su parte, la Carta de Banjul, en el continente africano, da génesis a su propio sistema de protección regional.

Estos regímenes regionales, especialmente el europeo -el más avanzado y revolucionario de todos- pero también el americano -por la práctica y la jurisprudencia de la Comisión y de la Corte que se observa en los últimos añosmuestran que los Estados firmantes ya no son libres de tratar a sus propios ciudadanos como crean que es apropiado, al estar obligados por los mecanismos propios de cada régimen internacional regional de protección. Se evidencia, por tanto, un cambio gradual en la protección de los derechos humanos que genera un alejamiento del principio que la soberanía del Estado debe salvaguardarse sin importar las implicancias en los individuos, grupos y organizaciones. El respeto de la autonomía de sujeto -individuo/ciudadano- y de una extensa gama de derechos humanos crea una nueva serie de principios ordenadores de los asuntos políticos, que puede delimitar y reducir el principio del poder efectivo del Estado.

\section{La Convención Americana de Derechos Humanos y el derecho a la información}

Quienes están bajo la protección de la Convención Interamericana de Derechos Humanos tienen un plexo de derechos y garantía consagrados. Entre todos ellos es interesante destacar lo que desde el ordenamiento jurídico internacional ha dado en denominarse como el derecho a la información, construcción jurídica superadora de la tradicional libertad de expresión ${ }^{5}$.

Se ha seleccionado este derecho debido a que su consagración ha tenido su génesis en el ámbito internacional (desde la Declaración de Derechos del Hombre y el Ciudadano de 1789 en forma embrionaria hasta su estructuración definitiva en el Pacto de Derechos Civiles y Políticos del sistema de ONU, para inmediatamente

El 18 de julio de ese año, cuando Grenada se constituyó en el onceavo Estado parte en depositar el respectivo documento de ratificación o adhesión, cumplimentando así lo establecido por el artículo 21 , inciso 3 de ese documento internacional.

5 El concepto de libertad de expresión corresponde al constitucionalismo clásico o liberal, mientras que el de Derecho a la Información se genera a partir de 1948, con la recepción en la Declaración Universal de los Derechos del Hombre (art. 19). La libertad de expresión sólo se ocupa de la garantía de difundir información o todo tipo de expresiones, propia del constitucionalismo liberal decimonónico, en tanto que el derecho a la información consiste en difundir, recibir y buscar información de toda índole, consagrando como titular del mismo al sujeto universal y no sólo comprensivo del propietario de los medios o de los trabajadores de los mismos. De todos modos son expresiones que junto con libertad de prensa y de imprenta suelen usarse indistintamente. 
consagrarse en el convenio protectorio de la región americana: art. 13, ap. 1). A partir de la consagración en el derecho internacional de los derechos humanos, luego se logra o proyecta a los ordenamientos jurídicos internos, produciendo la tensión entre el ordenamiento interno y el internacional. Este derecho humano universal consiste en el derecho de buscar, recibir y difundir ideas e informaciones de toda índole, así como también el de recibir y conocer las informaciones e ideas difundidas por los demás. De allí que tenga tanto una dimensión individual como social. Requiere, por un lado, que nadie sea arbitrariamente menoscabado o impedido de manifestar su propio pensamiento y representa, por tanto, un derecho de cada individuo; asimismo implica, un derecho colectivo a recibir cualquier información y a conocer la expresión del pensamiento ajeno. Su importancia radica en la impronta que la comunicación y la información han alcanzado en el mundo contemporáneo. Tan es así que se caracteriza a las sociedades actuales como sociedades de la información (Matellar, Castells). Por otra parte, los medios y la comunicación se han convertido en uno de los rasgos característicos de este mundo globalizado.

En las últimas décadas, el Sistema Interamericano de Protección de los Derechos Humanos, a través de la labor de sus dos órganos protectores (la Comisión Interamericana y la Corte Interamericana de Derechos Humanos) han producido informes y sentencias relacionadas con casos llevados por ciudadanos de la región en los que se pretendía el aggiornamiento del derecho interno de sus respectivos países respecto al consagrado a nivel regional, en materia de derecho a la información. Chile, Paraguay, Costa Rica y Argentina han sido los leading case, y en el caso argentino se han generado sentencias en el ámbito interno que recaban esa otra jurisprudencia regional para actualizar lo que la jurisdicción doméstica no protege produciendo importantes cambios legislativos.

\section{Incidencia del Sistema Interamericano de Protección de los Derechos Humanos en el derecho interno en materia de derecho de la información}

El nuevo escenario internacional produce lo que se ha dado en caracterizar como la globalización del derecho, especialmente en el ámbito de los derechos humanos. En este contexto se observa la incidencia del Sistema Interamericano de Protección de los Derechos Humanos, con especial énfasis en el derecho de la información, en el derecho interno.

En este sentido, la Corte Interamericana de Derechos Humanos ha señalado que quienes están bajo la protección de la Convención tienen el derecho de buscar, recibir y difundir ideas e informaciones de toda índole, así como también el de recibir y conocer las informaciones e ideas difundidas por los demás. Esta jurisprudencia ha sido sentada en los casos Kimel de 2009, que es el más reciente pero también se encuentra en otros anteriores tales como el caso Olmedo Bustos y 
otros vs. Chile de 2001, más conocido como "La Última Tentación de Cristo"; Caso Ivcher Bronstein de 1999; Caso Herrera Ulloa de 2001, Caso Ricardo Canese de 2004 y Caso Palamara Iribarne de 2005.

Es por ello que la libertad de expresión tiene una dimensión individual y una dimensión social: ésta requiere, por un lado, que nadie sea arbitrariamente menoscabado o impedido de manifestar su propio pensamiento y representa, por tanto, un derecho de cada individuo; pero implica también, por otro lado, un derecho colectivo a recibir cualquier información y a conocer la expresión del pensamiento ajeno. Sin embargo, no es un derecho absoluto. El artículo 13.2 de la Convención, que prohíbe la censura previa, también prevé la posibilidad de exigir responsabilidades ulteriores por el ejercicio abusivo de este derecho. Estas restricciones tienen carácter excepcional y no deben limitar, más allá de lo estrictamente necesario, el pleno ejercicio de la libertad de expresión y convertirse en un mecanismo directo o indirecto de censura previa.

Por su parte, el artículo 11 de la Convención establece que toda persona tiene derecho al respeto de su honra y al reconocimiento de su dignidad. Esto implica límites a las injerencias de los particulares y del Estado. Por ello, es legítimo que quien se considere afectado en su honor recurra a los medios judiciales que el Estado disponga para su protección. La necesidad de proteger los derechos a la honra y a la reputación, así como otros derechos que pudieran verse afectados por un ejercicio abusivo de la libertad de expresión, requiere la debida observancia de los límites fijados a este respecto por la propia Convención. Estos deben responder a un criterio de estricta proporcionalidad.

Dada la importancia de la libertad de expresión en una sociedad democrática y la elevada responsabilidad que ello entraña para quienes ejercen profesionalmente labores de comunicación social, el Estado no sólo debe minimizar las restricciones a la circulación de la información sino también equilibrar, en la mayor medida de lo posible, la participación de las distintas informaciones en el debate público, impulsando el pluralismo informativo. En consecuencia, la equidad debe regir el flujo informativo. En estos términos puede explicarse la protección de los derechos humanos de quien enfrenta el poder de los medios y el intento por asegurar condiciones estructurales que permitan la expresión equitativa de las ideas.

\section{El sistema americano frente al derecho a la información y su influencia en el derecho argentino}

El sistema americano ha tenido profunda influencia en el ordenamiento jurídico argentino en materia de derecho de la información en aspectos que hacen al derecho respuesta o rectificación y a delitos contra el honor como el desacato y las calumnias 
e injurias. Así es como la jurisprudencia de la Corte Suprema de Justicia de la Nación en materia de derecho de rectificación o de respuesta, se modifica a partir de Edmekdjian c/Sofovich (1992). Asimismo, el caso Verbitsky (1994) y el caso Kimel (2008). De este último se desprenden los casos: Daniel Alberto Bravo contra Myriam Esther Vallejos por "calumnias e injurias" resuelto por el Tribunal de Necochea el 26 de septiembre de 2008; "F., J. M. s/ incidente de excepción de falta de acción" resuelto por la Cámara Nacional del Crimen el 9 de marzo de2009; y el caso del periódico La Arena.; Stella Maris García contra Saúl Santesteban (director), Leonardo Santesteban (secretario de redacción) y Juan José Reyes (columnista) del mencionado periódico, en mayo 2009. Muestra la citada influencia no sólo en materia jurisprudencial sino que ha producido un reordenamiento jurídico en lo que hace a la modificación del Código Penal en materia de delitos contra el honor (desacato, injurias y calumnias) cuando se confrontan con la libertad de expresión y el derecho a la información que la Convención Americana consagra.

\subsection{Caso Kimel vs Argentina}

\subsubsection{Los hechos}

En 1999, el periodista Eduardo Kimel fue condenado por la Corte Suprema de Justicia a un año de prisión en suspenso y al pago indemnizatorio, que nunca se efectivizó, de veinte mil pesos por el delito de calumnias e injurias a raíz de la crítica realizada en su libro La Masacre de San Patricio, al desempeño del juez Guillermo Rivarola en la causa en la que se investigaba el asesinato de cinco religiosos en julio de 1976 en la iglesia San Patricio, en plena dictadura militar. Rivarola, a cargo de la investigación de esa causa entre los años 1976 y 1977, consideró que el libro elaborado por Kimel, tenía "imputaciones deshonrosas" en su contra, razón por la cual inició juicio al periodista. Para ello se amparó en la figura de delito penal de calumnia tal como se encontraba previsto en el Código Penal en el artículo 109 y que establecía que "la falsa imputación de un delito que dé lugar a la acción pública será reprimida con prisión de uno a tres años" ${ }^{\circ}$. Por su parte, el delito de injurias significa la "deshonra o desacreditación de otro", y según lo prescribe el artículo 110 del mismo Código, está penado "con hasta noventa mil pesos o prisión de un mes a un año"7. Asimismo, la normativa penal argentina expresaba que quien deba defenderse de la acusación de injurias, tendrá que probar la verdad de la imputación que realizó y si esta tenía como objetivo "defender o garantizar un interés público actual; o si el hecho atribuido hubiere dado lugar a un proceso penal”, según lo establece el artículo 111.

$6 \quad$ Código Penal de la República Argentina. La redacción citada corresponde al tipo penal antes de la reforma. La comparación de la normativa anterior y la modificada se transcribe en el presente trabajo en Anexo.

$7 \quad$ T.O Ley 24286. 
En diciembre de 2000, el Centro de Estudios Legales y Sociales CELS y el Centro para la Justicia y el Derecho Internacional CEJIL ("los peticionarios") presentan denuncia ante la Comisión Interamericana de Derechos Humanos en contra del Estado argentino en razón de la condena -expresada supra- a un año de prisión en suspenso y al pago de una indemnización de veinte mil pesos dictada en contra del periodista Eduardo Kimel. Se alega que el Estado ha violado los derechos a las garantías judiciales y a la libertad de expresión en relación con las obligaciones generales de respeto y garantía, y de adecuación de la legislación interna, consagrados en los artículos 8, 13, 1(1) y 2de la Convención Americana de Derechos Humanos. El 30 de julio de 2001 el Estado presentó una comunicación a la CIDH remitiendo copia de un proyecto de ley presentado por el Poder Ejecutivo al Congreso de la Nación, con el propósito de reformar las disposiciones contenidas en los Códigos Civil y Penal de la Nación en relación con los delitos de injurias y calumnias, para adaptarlas al propósito y fin de la Convención Americana. Dicha comunicación fue trasmitida a los peticionarios el 16 de agosto de 2001. En noviembre de 2002 los peticionarios solicitan a la Comisión que se declarara la admisibilidad de la denuncia en favor del Sr. Kimel, en virtud de vencer los plazos establecidos para la modificación del Código. En noviembre de 2003, la Comisión informó a las partes que daba por concluido el proceso de solución amistosa, en vista de la falta de resultados en el mismo, otorgándoles el plazo de un mes para que presentaran sus observaciones adicionales. Los peticionarios, reiterando su solicitud de que se declarara admisible el caso, alegan que el Estado ha incumplido con sus obligaciones bajo el artículo 2 de la Convención Americana, al aplicar en este caso particular los artículos 109 y 110 del Código Penal de la Nación, que penalizan las manifestaciones o expresiones críticas relativas a funcionarios públicos en el ejercicio de sus cargos, de manera similar a las leyes de desacato ya derogadas en el país, mientras que Argentina no contestó. La Comisión establece que tiene competencia ratione loci para conocer la petición, por cuanto en ella se alegan violaciones de derechos protegidos en la Convención Americana que habrían tenido lugar dentro del territorio de un Estado parte en dicho tratado. Pasa así a la Corte Interamericana, para sentenciar al respecto.

\subsubsection{Resolución de la Corte Interamericana}

El Alto Tribunal internacional, a nueve años de que la Corte Suprema de Justicia condenara al periodista Eduardo Kimel a un año de prisión en suspenso por los delitos de calumnias e injurias, le ordenó al Estado argentino que adecue su derecho interno a la Convención Americana sobre Derechos Humanos en cuanto a garantizar la libertad de expresión. Esto es, ordenó al Estado una reforma legal de los delitos de calumnias e injurias, y de las normas del Código Civil en lo relativo a su redacción y mejora de la "precisión" de las normas, ya que afectan el "principio de legalidad penal”. El juez integrante de la Corte, Diego García Sayán, calificó en su voto a la "injusta sanción penal" que dispuso la justicia argentina contra el periodista 
como el "aspecto medular de la responsabilidad internacional del Estado en este caso". Según su visión, el lenguaje que utilizó Kimel en su libro La masacre de San Patricio, no produce una crítica hacia la vida personal del juez Guillermo Rivarola, que fue quien lo demandó, sino que se refiere al trabajo realizado por el magistrado en la causa judicial en la que estaba a cargo. Otro integrante del Tribunal internacional, Sergio García Ramírez, propuso otros medios que no tuvieran que ver con la vía penal, para sancionar aquellas situaciones en las que se haya incurrido en el delito de calumnias e injurias. "Basta con poner en movimiento reacciones jurídicas de distinta naturaleza: administrativas y civiles... la sentencia civil condenatoria constituye, de suyo, una declaración de ilicitud no menos enfática y eficaz que la condena penal".

La Corte Interamericana señaló que la falta de exactitud de los artículos que tipifican los delitos en cuestión, "da vía libre para que los tribunales argentinos fallen con criterios discrecionales, fomentado el dictado de numerosas sentencias violatorias a la libertad de expresión". "La ambigüedad en la formulación de los tipos penales genera dudas y abre el campo al arbitrio de la autoridad". A su vez le ordenó que deje sin efecto la condena que pesaba sobre el periodista Eduardo Kimel, así como el pago de una indemnización por concepto de daño material e inmaterial -con diez mil dólares-, eliminar el nombre de Kimel de aquellos registros públicos en que figure con antecedentes penales y realizar un acto público de reconocimiento de su responsabilidad en la causa, en el plazo de seis meses, ya que consideró que la sentencia del Máximo Tribunal argentino avalaba la "violación a la libertad de expresión"8.

\subsection{Casos resueltos por los tribunales argentinos a partir de Kimel y antes de la reforma}

El caso Bravo contra Vallejos se erigió en el primer antecedente al respecto. En Necochea, el 26 de septiembre de 2008 se resuelve la querella que por "calumnias e injurias" promueve el señor Daniel Alberto Bravo contra la señora Myriam Esther Vallejos. Y allí el tribunal señala que el 2 de mayo de 2008 la Corte Interamericana de Derechos Humanos (CIDH) dictó sentencia en el caso "Kimel vs Argentina", donde estableció que los tipos penales previstos en los artículos 109 y 110 del Código Penal no respetan el principio de legalidad. El caso se resuelve declarando la anticonvencionalidad de la norma en cuestión.

Otro caso para citar es el de "F., J. M. s/ incidente de excepción de falta de acción”, resuelto por la Cámara Nacional Criminal y Correccional el 9 de marzo

8 En: www.corteidh.or.cr/docs/casos/articulos/seriec_177_esp.pdf puede encontrarse el texto completo de la sentencia del tribunal interamericano. 
de 2009. Argumenta la falta de acción en la causa incoada por aplicación del caso Kimel.

Finalmente se puede citar el caso La Arena de Santa Rosa, La Pampa. Stella Maris García contra Reyes Juan, Santiesteban Leonardo y Santiesteban Saul, de junio de $2009^{9}$. En esta causa, el juez Miguel Ángel Vagge sobresee a los periodistas Saúl Santesteban (director), Leonardo Santesteban (secretario de redacción) y Juan José Reyes (columnista) de La Arena. Lo realiza aceptando una solicitud del abogado defensor, Alberto José Acosta, para que se decrete la inconstitucionalidad y anticonvencionalidad de los artículos 109 y 110 del Código Penal, conforme lo resuelto por la Corte Interamericana de Derechos Humanos en el caso "Kimel”.

Este fallo tiene su origen en la querella entablada por Stella Maris García -junto a una demanda civil por daños y perjuicios- por sentirse agraviada por los dichos en un artículo periodístico realizado por Juan José Reyes publicado en enero de 2005. En el mismo se cuestionaba la vinculación de la fundación "Nuestros Pibes" que se hace cargo del instituto de menores Ipesa, para lo cual se construyó un edificio especial, en terrenos que esa entidad donó al Estado provincial, pero dicho inmueble estaría hipotecado a favor de la provincia en razón de un crédito que la fundación había tomado para un emprendimiento económico.

La entidad comenzó así a percibir decenas de miles de pesos por mes para gerenciar la institución estatal (830.000 pesos al cabo de un año), dato que el artículo conectaba con la anterior donación.

Durante el trámite de la causa, se dictó el fallo "Kimel". En razón de ello y a la jurisprudencia que se había generado a partir del mismo -a los que ya se ha hecho mención- es que el juez

concordó "con el planteo formulado por la defensa de los coquerellados, Dr. Alberto José Acosta, en cuanto a que los artículos 109 y 110 del Código Penal resultan inaplicables por violar el principio de legalidad", ya que "en dichos tipos penales no existe un parámetro objetivo para que una persona pueda medir y predecir la posible ilicitud de sus expresiones, sino que ello se remite a un juicio de valor subjetivo del juzgador" 10 .

Por ende se negó a aplicar esos artículos, ya que lo contrario "implicaría el juzgamiento en base de (sic) tipos penales que han sido declarados anticonvencionales

\footnotetext{
$9 \quad$ Ver http://www.diariouno.com.ar/edimpresa/2009/06/07/nota214873.html http://www.lacapital.com.ar/ed_impresa/2009/6/edicion_228/contenidos/noticia_5720.html

10 Ver http://www.diariouno.com.ar/edimpresa/2009/06/07/nota214873.html http://www.lacapital.com.ar/ed_impresa/2009/6/edicion_228/contenidos/noticia_5720.html
} 
y que el propio Estado argentino así lo ha reconocido", aceptando la obligación de corregir el Código Penal "para satisfacer los requerimientos de seguridad jurídica y, consecuentemente, no afectar el ejercicio del derecho a la libertad de expresión".

El fallo es vinculante y obliga al Estado argentino a obrar en consecuencia" ya que la Convención de Viena "establece que no puede invocarse ninguna norma de derecho interno para infringir una convención internacional”.

Asimismo el juez señala que "es de suma importancia destacar que en una democracia constitucional los principios de transparencia, rendición de cuentas y responsabilidad política constituyen la contrapartida necesaria de un gobierno representativo, en la que los ciudadanos puedan controlar los actos de quienes ejercen el gobierno. Va de suyo, por ello, que con el fin de que los ciudadanos puedan ejercer dicho control, la libertad de información es una libertad social claramente asociado al derecho a la libertad de expresión protegida por nuestra Constitución Nacional y los instrumentos internacionales incorporados a nuestra Carta Magna"11.

\subsection{Reforma legislativa de los tipos penales de calumnias e injurias. Ley $26551^{12}$}

A raíz de lo sentenciado por la Corte Interamericana de Derechos Humanos, el Poder Ejecutivo Nacional promueve la modificación del Código Penal en materia de delitos contra el honor enviando un Proyecto de Ley al Poder Legislativo, promulgado finalmente como Ley de la Nación el 26 de noviembre de 2009. En dicha modificación se reformulan las sanciones por cuanto la pena privativa de la libertad es reemplazada por multa, amparándose especialmente la difusión de información relacionada con asuntos de interés público y aquellas expresiones que no sean asertivas o que su contenido se atribuya sustancialmente fiel a la fuente pertinente.

\subsection{La primera causa aplicando la normativa reformada del Código Penal}

Es la causa No 1962 /09 “K., D. G. s/ desestimación” resuelta el primero de febrero de 2010, y en la que es importante destacar los dichos del juez Julio Marcelo Lucini $^{13}$ que aplica el principio de retroactividad de la norma más benigna. Por cuanto la reforma legislativa de los tipos penales de calumnias e injurias promulgada el 26 de noviembre de 2009 modifica y restringe los supuestos abarcados por los

\footnotetext{
11 Ver http://www.diariouno.com.ar/edimpresa/2009/06/07/nota214873.html http://www.lacapital.com.ar/ed_impresa/2009/6/edicion_228/contenidos/noticia_5720.html 
artículos 109 y 110 del Código Penal, consignándose que en ningún caso configurarán delito “... las expresiones referidas a asuntos de interés público o las que no sean asertivas" y "... tampoco (...) los calificativos lesivos del honor cuando guardasen relación con un asunto de interés público" (confr. artículos $1^{\circ}$ y $2^{\circ}$ de la ley 26.551).

Si bien esta norma no se hallaba vigente al momento de los sucesos tratados en la causa, debe aplicarse retroactivamente ya que se trata de una ley más benigna (artículo $2^{\circ}$ del Código Penal). La conducta que habría desplegado el querellado no configura una acción típica, a la luz de la nueva legislación que rige en la materia, toda vez que los comentarios presuntamente lesivos realizados contra el querellante, vinculados a su desempeño como director del Hospital, resultan actividades que constituyen asuntos de interés público. En igual sentido y con antelación a la modificación legal operada, se había expedido la Corte Interamericana en el fallo "Kimel" de fecha 2 de mayo de 2008. En aquel caso se encontraban en juego los derechos a la libertad de expresión y al honor presuntamente violado y debe atenderse a los postulados del pronunciamiento mencionado desde la fecha en que fue dictado por el Tribunal internacional encargado de la interpretación y aplicación de la Convención Americana sobre Derechos Humanos, con jerarquía constitucional a partir de la reforma de nuestra Constitución Nacional en el año 1994 (art. 75, inc. 22).

Allí se expuso que: "respecto al derecho a la honra, las expresiones concernientes a la idoneidad de una persona para el desempeño de un cargo público o a los actos realizados por funcionarios en el desempeño de sus labores gozan de mayor protección, de manera tal que se propicie el debate democrático. La Corte ha señalado que en una sociedad democrática los funcionarios públicos están más expuestos al escrutinio y la crítica del público. Este diferente umbral de protección se explica porque se han expuesto voluntariamente a un escrutinio más exigente. Sus actividades salen del dominio de la esfera privada para insertarse en la esfera del debate público. Este umbral no se asienta en la calidad del sujeto, sino en el interés público de las actividades que realiza..."... "en la arena del debate sobre temas de alto interés público, no sólo se protege la emisión de expresiones inofensivas o bien recibidas por la opinión pública, sino también la de aquéllas que chocan, irritan o inquietan a los funcionarios públicos o a un sector cualquiera de la población. En una sociedad democrática, la prensa debe informar ampliamente sobre cuestiones de interés público, que afectan bienes sociales, y los funcionarios rendir cuentas de su actuación en el ejercicio de sus tareas públicas" ${ }^{14}$.

14 El juez Lucini, en su voto, hace referencia a los párrafos 86 y 88 del caso Kimel vs Argentina, referenciado en nota 8 . 
De este modo, se impone equiparar a la figura de trascendencia pública con la de un funcionario estatal -con el diferente "umbral" de protección aludido-.

En esta causa ${ }^{15}$ se desecha categóricamente la configuración de los delitos de calumnias e injurias cuando las expresiones atribuidas al acusado se refieran a asuntos de interés público o no sean asertivas. Puede observarse la primera de estas situaciones, pues se vincula con los dichos vertidos por un legislador de la Ciudad de Buenos Aires para criticar -si bien con fuertes expresiones- la designación de un funcionario público en la misma órbita estatal. Se pronuncia de tal modo por medio de manifestaciones vertidas en un reportaje periodístico, acudiendo a un pretérito desempeño del querellante vinculado con presuntas irregularidades que motivaran una investigación judicial y donde, en definitiva, se lo sobreseyera sin haber sido siquiera citado a prestar declaración, conforme dichos del propio acusador y copia de la resolución liberatoria.

En esta dirección cabe interpretar entonces que el querellado realizó expresiones acerca de un asunto de interés público, desde que se trata de su concepto referente al desenvolvimiento profesional del querellante en la órbita de un organismo dependiente de la comuna metropolitana, lo que las excluye del marco típico delineado para las figuras de calumnias e injurias actualmente en vigencia. No incide, al menos en la esfera del derecho penal, que la actuación de quien se considera agraviado haya sido materia de un pronunciamiento judicial que la considerara lícita, pues la crítica del reprochado, aun con los ácidos y mordaces ribetes que parece presentar no encuadra hoy, en razón de lo expuesto, dentro de la adecuación típica en las que se ha pretendido insertárselas. Por el contrario, la prohibición expresa de criminalización que consagran las normas contenidas en los reformados artículos 109 y 110, veda la persecución penal por manifestaciones de las características enunciadas cuando guardan relación con un asunto de interés público, como es el caso.

Es importante aquí destacar en la sentencia la forma en que se ocupa de esclarecer el concepto de "interés público" 16 y se destaca la vasta doctrina autorizada que se ha ocupado del tema. Especialmente se ocupa del tema el Juez González, en su voto, al apoyarse en la doctrina y citar que: “...Debe trazarse una distinción en las ofensas entre sujetos privados y las de interés general...Las comprobaciones criminológicas sobre el funcionamiento del sistema penal pueden ser aplicadas solamente a los casos donde la expresión enjuiciada supera el conflicto interpersonal

\footnotetext{
15 Voto del Juez Carlos A. González en causa № 1962 /09 “K., D. G. s/ desestimación”. http:// www.pjn.gov.ar/Publicaciones/00017/00033562.Pdf

16 Voto del Juez Carlos A. González en causa No 1962 /09 “K., D. G. s/ desestimación”. http:// www.pjn.gov.ar/Publicaciones/00017/00033562.Pdf
} 
y se inscribe en un marco que interesa a los demás miembros de la comunidad...[De Luca "Libertad de prensa y delitos contra el honor: delitos contra el honor cometidos a través de la prensa", 1a. edición, Ad-Hoc, Buenos Aires, 2006, p. 53]. Julio César Rivera (h) considera que “....aun cuando el que habla o escribe esté motivado por odio o mala voluntad, su expresión está protegida por la libertad de expresión, cuando se trata de cuestiones de interés público [...]...cabe señalar que tanto el funcionario público como la figura pública (vinculada a una cuestión de interés público) asumen voluntariamente una posición en donde se encuentran más expuestos a la crítica y a los ataques. No se puede ejercer un trabajo que implica la adopción de decisiones relacionadas con el bienestar de la sociedad y que afectan a...todos o gran parte de los ciudadanos y al mismo tiempo pretender estar exento de críticas y ataques por parte de aquellas personas que no están de acuerdo con las decisiones tomadas... [Rivera (h), Julio César, "El derecho de crítica en cuestiones de interés público y el delito de injurias", publicado en La Ley Litoral, 01/01/2002, 1268]. Gil Lavedra y Alicia Cano en "Un paso positivo. Comentario a la ley 26.551" plantean "...La importancia de la descriminalización de las expresiones sobre asuntos de interés público obedece al peligro del cercenamiento del debate político con las consecuencias desfavorables que ello acarrea para el sistema democrático, en la necesidad de evitar la inhibición de la expresión por está protegida por la libertad de expresión, cuando se trata de cuestiones de interés público [...] ...cabe señalar que tanto el funcionario público como la figura pública (vinculada a una cuestión de interés público) asumen voluntariamente una posición en donde se encuentran más expuestos a la crítica y a los ataques. No se puede ejercer un trabajo que implica la adopción de decisiones relacionadas con el bienestar de la sociedad y que afectan a...todos o gran parte de los ciudadanos y al mismo tiempo pretender estar exento de críticas y ataques por parte de aquellas personas que no están de acuerdo con las decisiones tomadas... (Gil Lavedra, Ricardo - Cano, Alicia, "Un paso positivo. Comentario a la ley 26.551", La Ley, Buenos Aires, 07/12/2009, p.1).- Por lo tanto el interés público está vinculado con el buen funcionamiento del sistema democrático, el respeto a los principios y reglas de un estado de derecho, las garantías de los derechos individuales y colectivos, la intervención del ciudadano en los asuntos del quehacer público, y todo otro tema análogo que se relacione con estos tópicos. A ello parece haber atendido el legislador para limitar la censura en los asuntos que revisten estas particularidades, como lo es el supuesto bajo análisis en estas actuaciones.- En síntesis, la nueva normativa consagra una prohibición expresa de criminalización para las conductas objetivamente ofensivas del honor cuando éstas se manifiesten con los fines y las formas especificadas en los reformados artículos 109 y 110 de la ley de fondo, sin perjuicio de las acciones que pueda intentar, quien se considera ofendido, en otra sede judicial ${ }^{17}$.

17 Voto del Juez Carlos A. González en causa N 1962 /09 “K., D. G. s/ desestimación”. http:// www.pjn.gov.ar/Publicaciones/00017/00033562.Pdf 
Derecho y Realidad

\section{Conclusión}

La Comisión y la Corte Interamericanas de Derechos Humanos han remarcado que si una ley resulta incompatible con la Convención, el Estado parte está obligado, de conformidad con el artículo 2, a adoptar las medidas legislativas necesarias para hacer efectivos los derechos y libertades garantizados por la Convención. De allí que el Estado argentino estaba obligado a reformular los delitos contra el honor tipificados en el Código Penal. El fundamento de la despenalización de las expresiones que se refieran a temas, asuntos o problemáticas de interés público, reside en la importancia del debate público cuyo cercenamiento implicaría consecuencias negativas en un país que se precie democrático, por ello es de suma importancia que la libertad de expresión esté tutelada enfáticamente cuando se trata de cuestiones de interés público.

La Ley 26.551, modificatoria del Código Penal de la República Argentina, si bien representa un avance en cumplimiento de lo dispuesto por la Corte Interamericana de Derechos Humanos en el caso Kimmel, no completa lo resuelto ya que para ello también debería reformarse el Código Civil para evitar la utilización arbitraria y desproporcionada de las indemnizaciones pecuniarias que cercenan la libertad de expresión tanto de los medios de comunicación, como de los periodistas y de los ciudadanos en general.

Con todo, lo presentado en este trabajo es un análisis de casos en el que se observa la influencia del sistema protectorio regional a nivel continental de los derechos humanos en la jurisprudencia y en la legislación interna de uno de los Estados miembro de ese régimen internacional, lo que sirve para demostrar la tesis postulada en esta presentación. 


\section{Anexo \\ Comparación entre la legislación penal anterior y posterior al caso Kimel}

Art. 109. La calumnia o falsa imputación a una persona física determinada de la comisión de un delito concreto y circunstanciado que dé lugar a la acción pública, será reprimida con multa de pesos tres mil $(\$ 3.000)$ a pesos treinta mil $(\$ 30.000)$. En ningún caso configurarán delito de calumnia las expresiones referidas a asuntos de interés público o las que no sean asertivas. (Texto conforme la ley 26551)

Texto anterior: La calumnia o falsa imputación de un delito que dé lugar a la acción pública, será reprimida con prisión de uno a tres años.

Art. 110. El que intencionalmente deshonrare o desacreditare a una persona física determinada será reprimido con multa de pesos mil quinientos $(\$ 1.500)$ a pesos veinte mil (\$20.000). En ningún caso configurarán delito de injurias las expresiones referidas a asuntos de interés público o las que no sean asertivas. Tampoco configurarán delito de injurias los calificativos lesivos del honor cuando guardasen relación con un asunto de interés público. (Texto conforme la ley 26551)

Texto anterior: El que deshonrare o desacreditare a otro, será reprimido con multa de mil quinientos a noventa mil pesos o prisión de un mes a un año. (Multa según ley 24.286)

Art. 111. El acusado de injuria, en los casos en los que las expresiones de ningún modo estén vinculadas con asuntos de interés público, no podrá probar la verdad de la imputación salvo en los casos siguientes:

1) Si el hecho atribuido a la persona ofendida, hubiere dado lugar a un proceso penal.

2) Si el querellante pidiera la prueba de la imputación dirigida contra él.

En estos casos, si se probare la verdad de las imputaciones, el acusado quedará exento de pena. (Texto conforme la ley 26551)

Texto anterior: El acusado de injuria sólo podrá probar la verdad de la imputación en los casos siguientes:

1. Si la imputación hubiere tenido por objeto defender o garantizar un interés público actual;

2. Si el hecho atribuido a la persona ofendida, hubiere dado lugar a un proceso penal;

3. Si el querellante pidiere la prueba de la imputación dirigida contra él. 
En estos casos, si se probare la verdad de las imputaciones, el acusado quedará exento de pena.

\section{Art. 112. Derogado por ley 26551}

Texto anterior: El reo de calumnia o injuria equívoca o encubierta que rehusare dar en juicio explicaciones satisfactorias sobre ella, sufrirá del mínimum a la mitad de la pena correspondiente a la calumnia o injuria manifiesta.

Art. 113. El que publicare o reprodujere, por cualquier medio, injurias o calumnias inferidas por otro, será reprimido como autor de las injurias o calumnias de que se trate, siempre que su contenido no fuera atribuido en forma sustancialmente fiel a la fuente pertinente. En ningún caso configurarán delito de calumnia las expresiones referidas a asuntos de interés público o las que no sean asertivas. (Texto conforme la ley 26551)

Texto anterior: El que publicare o reprodujere, por cualquier medio, injurias o calumnias inferidas por otro, será reprimido como autor de las injurias o calumnias de que se trate.

Art. 114. Cuando la injuria o calumnia se hubiere propagado por medio de la prensa, en la Capital y territorios nacionales, sus autores quedarán sometidos a las sanciones del presente Código y el juez o tribunal ordenará, si lo pidiere el ofendido, que los editores inserten en los respectivos impresos o periódicos, a costa del culpable, la sentencia o satisfacción.

Art. 115. Las injurias proferidas por los litigantes, apoderados o defensores, en los escritos, discursos o informes producidos ante los tribunales y no dados a publicidad, quedarán sujetas únicamente a las correcciones disciplinarias correspondientes.

Art. 116. Cuando las injurias fueren recíprocas, el tribunal podrá, según las circunstancias, declarar exentas de pena a las dos partes o a alguna de ellas.

Art. 117. El acusado de injuria o calumnia quedará exento de pena si se retractare públicamente, antes de contestar la querella o en el acto de hacerlo. La retractación no importará para el acusado la aceptación de su culpabilidad. (Texto conforme la ley 26551)

Texto anterior: El culpable de injuria o calumnia contra un particular o asociación, quedará exento de pena, si se retractare públicamente, antes de contestar la querella $o$ en el acto de hacerlo. 


\section{Art. 117 bis.}

1. El inciso primero ha sido derogado por la ley 26.388 .

Texto anterior: Será reprimido con la pena de prisión de un mes a dos años el que insertara o hiciera insertar a sabiendas datos falsos en un archivo de datos personales.

2. La pena será de seis meses a tres años, al que proporcionara a un tercero a sabiendas información falsa contenida en un archivo de datos personales.

3. La escala penal se aumentará en la mitad del mínimo y del máximo, cuando del hecho se derive perjuicio a alguna persona.

4. Cuando el autor o responsable del ilícito sea funcionario público en ejercicio de sus funciones, se le aplicará la accesoria de inhabilitación para el desempeño de cargos públicos por el doble del tiempo que el de la condena. (Incorporado por ley 25.326)

\section{Lista de Referencias}

AA.VV. (1980). Corte Interamericana de Derechos Humanos. Seminario regional referente a la Convención Americana sobre Derechos Humanos. Secretaría General, OEA, Washington.

Arenal, C. del. (2002). Introducción a las relaciones internacionales. Madrid: Tecnos.

Barbé, E. (1995). Relaciones internacionales. Madrid: Tecnos.

Bonetto, M.S. \& Piñero, M.T. (2003). Las transformaciones del Estado. De la modernidad a la globalización. (2a ed.). Córdoba: Advocatus.

Borgarello, E.S. et al. (2009). Consideraciones acerca del derecho de la información. ( $2^{\circ}$ ed.). Córdoba: Ipso.

Cassese, A. (1993). Los derechos humanos en el mundo contemporáneo. Barcelona: Ariel.

Castells, M. (1998). La era de la información. Economía, sociedad y cultura. La sociedad red. Vol. I. Madrid: Alianza.

Colautti, C. (1986b). El Pacto de San José de Costa Rica y la libertad de expresión. La Ley, 911.

Duhalde, L.E. (1999). Teoría jurídico-política de la comunicación. Buenos Aires: Eudeba.

Ekmekdjian, M.A. (1998). Derecho a la información. Buenos Aires: Depalma.

Fayt, C.S. (1995). La omnipotencia de la prensa. Su juicio de realidad en la jurisprudencia argentina y norteamericana. Buenos Aires: La Ley.

Feldman, G.E. (1997). El Pacto de San José de Costa Rica. Santa Fe: RubinzalCulzoni. 
Ferreres, V. (2003). La eficacia de los derechos constitucionales, en los derechos fundamentales. Buenos Aires: Editores del Puerto.

Ferry, J.M. et al. (1992). El nuevo espacio público. Buenos Aires: Gedisa.

Hasenclever, A., Mayer, P. \& Rittberger, V. (1999). Las teorías de los regímenes internacionales: situación actual y propuestas para una síntesis. Foro Internacional, (158).

Held, D., Mc Grew, A. et al. (2002). Transformaciones globales. Política, cultura y economía. México: Oxford University Press.

Hoffmann, S. (1963). Teorías contemporáneas de las relaciones internacionales. Madrid: Tecnos.

Juárez, C.A. (2009, dic.). Derechos humanos y relaciones internacionales: reflexiones sobre el entrecruzamiento de estas disciplinas en la teoría y prácticas internacionales. En Anuario XI. (pp. 351-365). Córdoba: Centro de Investigaciones Jurídicas y Sociales de la UNC.

Juárez, C.A. (2009, mayo). A sesenta años de la Declaración Universal de Derechos Humanos: reflexiones para el debate. Breviario de Relaciones Internacionales, (12). Universidad Nacional de Córdoba. Recuperado de de www.cea.unc.edu.ar/boletin

Juárez, C.A. (2003). Derecho constitucional y relaciones internacionales. En: Haro, R. et al. (ed.). Curso de derecho constitucional argentino. Tomo I. Córdoba: Advocatus.

Lochard, G. \& Boyer, H. (2004). La comunicación mediática. Barcelona: Gedisa.

Loretti, D.M. (1999). El derecho a la información. Buenos Aires: Paidós.

Matellart, A. (1998). La mundialización de la comunicación. Barcelona: Paidós.

Matellart, A. (2003). Historia de la sociedad de la información. Buenos Aires: Paidós.

Quiroga, H. (2002). Derecho constitucional. Buenos Aires: Depalma.

Ramonet, I. (1997). La tiranía de la comunicación. Madrid: Debate.

Serna, P. \& Toller, F. (2000). La interpretación constitucional de los derechos fundamentales. Una alternativa a los conflictos de derechos. Buenos Aires: La Ley.

Ulanovsky, C. (2005). Historia de los medios de comunicación en Argentina. Paren las rotativas (1970-2000). (1 ${ }^{\text {a }}$ ed.). Buenos Aires: Emecé.

Vanossi, J.R. \& Dalla Vía, A. (2002). Régimen constitucional de los tratados. Buenos Aires: Abeledo-Perrot.

Vega, J.C. Graham, M.A. (1996). Jerarquía constitucional de los tratados internacionales. Buenos Aires: Astrea.

Verbitsky, H. (1997). Un mundo sin periodistas. Planeta, Espejo de la coyuntura. 